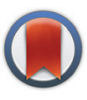

CrossMark $\leftarrow$ click for updates

Cite this: Org. Biomol. Chem., 2016, 14, 9907

Received 21st September 2016, Accepted 26th September 2016

DOI: $10.1039 / \mathrm{c} 6 \mathrm{ob} 02074 \mathrm{~g}$

www.rsc.org/obc

\title{
Denitrogenative hydrofluorination of aromatic aldehyde hydrazones using (difluoroiodo)toluene $\uparrow$
}

\author{
Kaivalya G. Kulkarni, Boris Miokovic, Matthew Sauder and Graham K. Murphy*
}

An operationally simple conversion of aromatic aldehyde hydrazones to monofluoromethylated arenes is reported. The hypervalent iodine reagent TollF $F_{2}$ serves as an oxidant, converting the hydrazone to the corresponding diazo compounds. The by-product of the oxidation process, HF, is consumed in situ by a denitrogenative hydrofluorination reaction of the diazo group.

\section{Introduction}

There is only a handful of naturally occurring fluorocarbons, so fluorine's use in medicinal chemistry might never have come to pass had chemists limited themselves to naturallyinspired pharmaceuticals. ${ }^{1}$ As fluorine is small, univalent and makes very strong bonds to carbon, it is now routinely employed as a biostere for hydrogen. ${ }^{2}$ Over the past few decades, site-specific fluorination has become an essential tool for medicinal chemists due to fluorine's ability to act as a biostere, and because of its desirable effects on the lipophilicity, metabolic stability and bioavailability of pharmaceutical and agrochemical agents. ${ }^{3}$

Given the breadth of biologically active fluorinated compounds, ${ }^{4}$ the development of new fluorination strategies and reagents remains an important field of research. ${ }^{5}$ As a complement to nucleophilic fluorination strategies, a large body of research developing electrophilic fluorinating reagents has been completed. While elemental fluorine is the simplest and most direct source of electrophilic fluorine, it is toxic, explosively reactive with organic compounds, and cannot be used without specialized laboratory equipment. To mitigate fluorine's reactivity, chemists have synthesized designer electrophilic fluorinating reagents based on $\mathrm{N}-\mathrm{F},{ }^{6} \mathrm{~S}-\mathrm{F},{ }^{7}$ and I-F bonds ${ }^{8,9}$ (Fig. 1). However, contrary to the N-F reagents (1-3) that serve as sources of electrophilic " $\mathrm{F}^{+}$", the S-F and I-F compounds (4-8) have umpolung reactivity: attack of the hypervalent sulphur or iodine atom by a Lewis base expels fluoride, and generates an electrophilic adduct to be displaced by the fluoride anion.

Benzylic fluorides, represented by the $\mathrm{ArCH}_{2} \mathrm{~F}, \mathrm{ArCF}_{2} \mathrm{H}$ and $\mathrm{ArCF}_{3}$ groups, ${ }^{10}$ are common synthetic targets and strategies

Department of Chemistry, University of Waterloo, 200 University Ave. W, Waterloo, ON, Canada, N2L3G1.E-mail: graham.murphy@uwaterloo.ca

$\dagger$ Electronic supplementary information (ESI) available: Experimental procedures and NMR spectra. See DOI: 10.1039/c6ob02074g

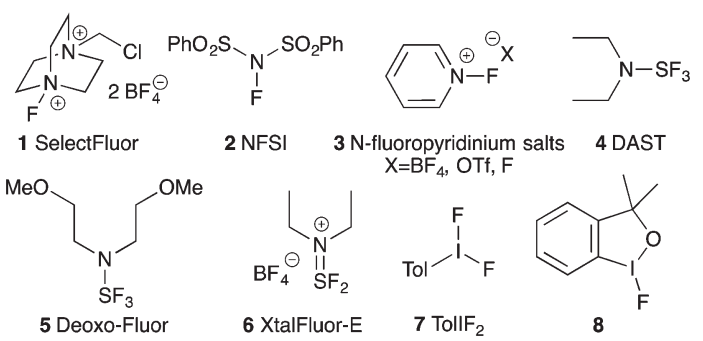

Fig. 1 Fluorine transfer reagents based on N-F, S-F or I-F bonds.

towards the $\mathrm{ArCH}_{2} \mathrm{~F}$ and $\mathrm{ArCF}_{2} \mathrm{H}$ functional groups have received considerable attention in the literature. ${ }^{5 a, h, 11}$ General strategies towards their synthesis include deoxygenative fluorination of benzyl alcohol (using 4-6), ${ }^{12}$ substitution reactions of benzyl halides, ${ }^{13}$ metal-catalyzed cross-coupling of fluorinecontaining units, ${ }^{3 a, 14}$ or radical-based fluorination reactions. ${ }^{15}$ The $\mathrm{ArCH}_{2} \mathrm{~F}$ group might also be synthesized by the hydrofluorination reaction of diazo compounds, simply by treating them with $\mathrm{HF}$ sources $\left(\mathrm{Et}_{3} \mathrm{~N} \cdot 3 \mathrm{HF}, \mathrm{Py} \cdot \mathrm{HF}, \mathrm{HBF}_{4}\right.$, etc. $) .{ }^{16}$ This reaction is highly effective for stabilized diazo compounds (e.g. flanked by two Ar, carbonyl, $\mathrm{CF}_{3}$ groups); however, the aryldiazomethanes required to synthesize benzylic monofluorides are unstable, rarely isolable, and cannot easily serve as hydrofluorination precursors. Nonetheless, development of this methodology could offer a mild, rapid and metal-free approach to benzylic monofluorides from simple starting materials.

Recently Yadav and co-workers reported a novel reaction where tosylhydrazone derivatives of aromatic aldehydes were converted to diazo intermediates in situ, and then treated with $\mathrm{Et}_{3} \mathrm{~N} \cdot 3 \mathrm{HF}$ to produce hydrofluorination products 10 (Fig. 2a). ${ }^{17}$ In an earlier study, Myers reported the oxidation of TBS-hydrazones to aryldiazomethanes using (difluoroiodo)benzene, and their subsequent hydroacylation with carboxylic acids (Fig. 2b). ${ }^{18}$ By combining these two concepts, we have 




(a)

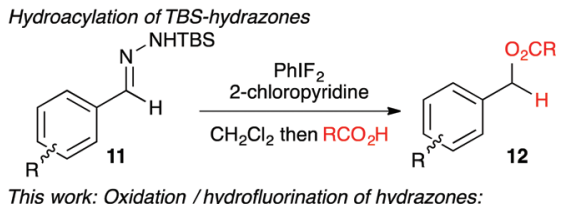

This work: Oxidation /hydrofluorination of hydrazones:

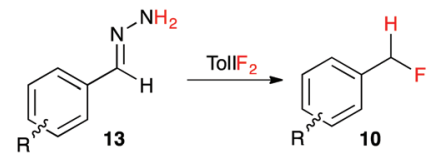

Fig. 2 In situ synthesis of aryldiazomethanes with subsequent hydrofunctionalization by acidic nucleophiles.

developed the first synthesis of benzyl fluorides where the hypervalent iodine reagent, TolIF $_{2}$, acts as both an oxidant and as the fluoride source, and gives $\mathbf{1 0}$ under mild and operationally simple reaction conditions (Fig. 2c).

\section{Results and discussion}

Our studies of halogenation reactions using $\mathrm{PhICl}_{2}$ or $\mathrm{TolIF}_{2}$ as halogen sources have led to the gem-dihalogenation of diazocarbonyl compounds ${ }^{19}$ and the oxidative dichlorination of isatin-3-hydrazones. ${ }^{20}$ The gem-difluorination reactions of diazoesters proceeded best using Lewis acid activation of $\mathrm{TolIF}_{2}$ with $\mathrm{BF}_{3} \cdot \mathrm{OEt}_{2}{ }^{19 c}$ or borosilicate glass ${ }^{21}$ (eqn (1)). Similarly, the oxidative difluorination reactions of benzaldehyde hydrazone 13a proceeded best with $\mathrm{TiF}_{3}$ activation of the iodane (eqn (2)). ${ }^{22}$ During these latter studies, we observed for the first time traces of hydrofluorination by-product 10a, which we attributed to the HF generated during the oxidation ${ }^{23}$ competing with TolIF $_{2}$ as an electrophilic partner for the diazo intermediate. We believed that this intermediate could be induced to react preferentially to give 10a through chemoselectivityguided modification of the reaction conditions.
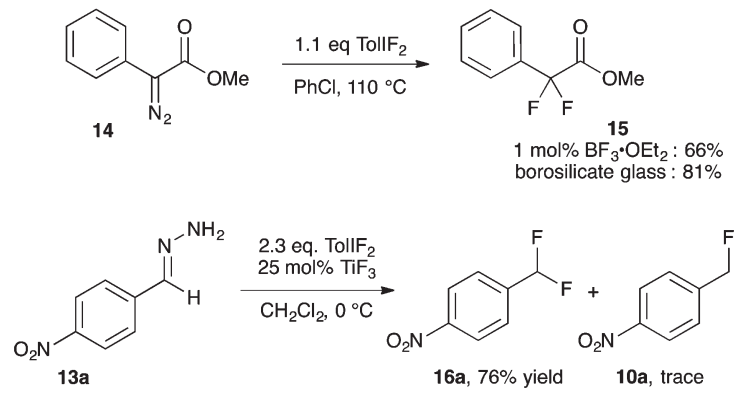

Due to the increased stability of the putative diazo intermediate, hydrazone 13a was used as our model substrate during the reaction optimization. We first studied the effects of Lewis acid activators on the reaction, in both laboratory glassware and PFA vials, using the optimal conditions previously determined in our gem-difluorination reactions. ${ }^{19 c, 21,22}$ Treating 13a with TolIF 2 and $1 \mathrm{~mol} \% \mathrm{BF}_{3} \cdot \mathrm{OEt}_{2}$ generally failed in both types of reaction vessel, and gave aldehyde 17a as the major product (Table 1, entries 1 and 2). The reactions were repeated using $\mathrm{TiF}_{3}$ as the activator, and while the reaction in glassware was very low yielding, the reaction in PFA gave 10a in $48 \%$ yield, along with $25 \%$ of aldehyde 17 a (Table 1 , entries 3 and 4). The experiment conducted in glassware without a Lewis acidic activator was also very low yielding, ${ }^{21}$ but the analogous reaction in a PFA vial proceeded in $47 \%$ yield (Table 1 , entries 5 and 6).

Mass spectrometry analysis of the crude reaction mixtures of these preliminary trials revealed the occasional occurrence of a hydrofluorinated dimerization product. To preclude dimer

Table 1 Optimization of the denitrogenative hydrofluorination reaction

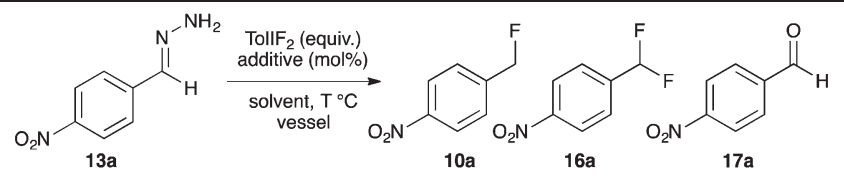

\begin{tabular}{|c|c|c|c|c|c|c|c|c|}
\hline Entry & Vessel & TolIF $_{2}$ (equiv.) & Additive (mol\%) & Solvent & Temp. $\left({ }^{\circ} \mathrm{C}\right)$ & Yield $^{a}$ 10a & Yield $^{a} \mathbf{1 6 a}$ & Yield $^{a} \mathbf{1 7 a}$ \\
\hline 1 & Glass $^{b}$ & 1.1 & $1 \% \mathrm{BF}_{3} \cdot \mathrm{OEt}_{2}$ & PhCl & 110 & $5 \%$ & $18 \%$ & $71 \%$ \\
\hline 2 & $\mathrm{PFA}^{c}$ & 1.1 & $1 \% \mathrm{BF}_{3} \cdot \mathrm{OEt}_{2}$ & DCM & 40 & $22 \%$ & - & $55 \%$ \\
\hline 3 & Glass & 1.1 & $25 \% \mathrm{TiF}_{3}$ & DCM & 40 & $10 \%$ & $19 \%$ & $34 \%$ \\
\hline 4 & PFA & 1.1 & $25 \% \mathrm{TiF}_{3}$ & DCM & 40 & $48 \%$ & - & $25 \%$ \\
\hline 5 & Glass & 1.1 & - & $\mathrm{PhCl}$ & 110 & $22 \%$ & $10 \%$ & $44 \%$ \\
\hline 6 & PFA & 1.1 & - & DCM & 40 & $47 \%$ & - & $6 \%$ \\
\hline $7^{d}$ & PFA & 1.1 & $25 \% \mathrm{TiF}_{3}$ & DCM & 40 & $48 \%$ & - & $19 \%$ \\
\hline $8^{d}$ & PFA & 1.1 & - & DCM & 40 & $60 \%$ & $5 \%$ & $12 \%$ \\
\hline $9^{d}$ & PFA & 1.5 & - & DCM & 40 & $61 \%$ & $10 \%$ & $15 \%$ \\
\hline $10^{d}$ & PFA & 1.7 & - & DCM & 40 & $74 \%$ & $11 \%$ & $12 \%$ \\
\hline $11^{d}$ & PFA & 2.1 & - & DCM & 40 & $71 \%$ & $15 \%$ & $11 \%$ \\
\hline
\end{tabular}

${ }^{a}$ Isolated yields. ${ }^{b}$ Reaction carried out in a borosilicate round bottom flask. ${ }^{c}$ Reaction carried out in a 4 mL PFA vial. ${ }^{d}$ Reverse addition of hydrazone to TolIF 2 . 
formation by minimizing the concentration of substrate relative to electrophile, the two most promising trial reactions (entries 4 and 6) were repeated using reverse addition of the hydrazone. The reaction using $\mathrm{TiF}_{3}$ was unchanged (entry 7), but the reaction without a Lewis acid activator gave 10a in 60\% yield (entry 8). These two trials (entries 6 and 8) were our first examples of fluorination reactions occurring in a PFA vessel in the absence of a Lewis-acidic activator. Presumably this is due to TolIF ${ }_{2}$ acting solely as an oxidant, instead of as an electrophilic fluorine source, for which Lewis acid activation is unnecessary. ${ }^{18}$ We completed our reaction optimization by varying the loading of the TolIF 2 (entries 9-11). While the production of the aldehyde by-product 17a was unchanged with increasing TolIF $_{2}$ loading, the amount of benzylic difluoride (16a) increased with increasing TolIF ${ }_{2}$ loading. This is consistent with our expectation that the gem-difluorination reaction should compete with hydrofluorination in the presence of excess TolIF $_{2}$. The highest yield (74\%) of the desired benzylic fluoride 10a was achieved when 1.7 equivalents of iodane was used.

Having demonstrated that benzaldehyde hydrazones could be induced to react preferentially via the denitrogenative hydrofluorination reaction, we next investigated the reaction efficacy on a variety of substituted benzaldehyde hydrazone derivatives (Scheme 1). The para-, meta- and ortho-nitro substituted substrates all performed well, as did the di-substituted derivatives having a meta- $\mathrm{NO}_{2}$ substituent, giving the products 10a-e in $51-74 \%$ yield. The para-carbomethoxy and para- or meta-cyano substituted benzylic fluorides $(\mathbf{1 0 f}-\mathbf{h})$ were isolated in good yield, as were the benzylic fluorides of the para-tosylate, para-

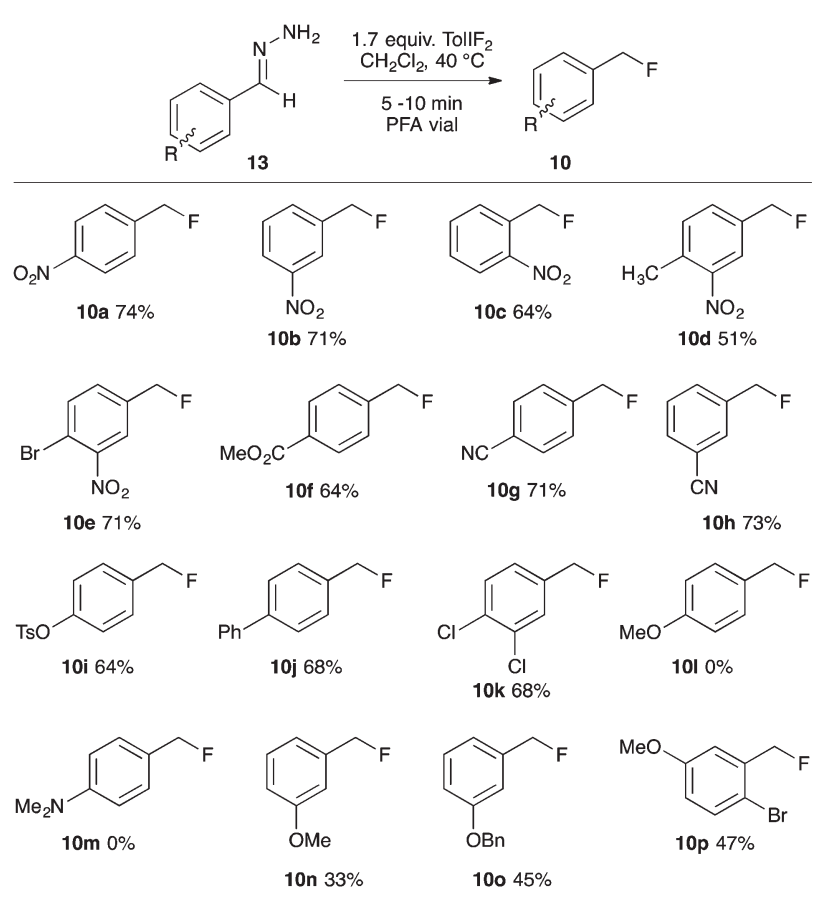

Scheme 1 Denitrogenative hydrofluorination of benzaldehyde hydrazone derivatives.

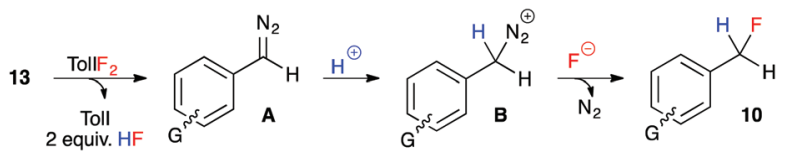

Fig. 3 Plausible mechanistic pathway for the conversion of hydrazones to benzylic fluorides.

phenyl and 3,4-dichloro substrates (10i-k). The para-methoxy and para-dimethylamino benzaldehyde hydrazones substrates were consumed by the action of $\mathrm{TolIF}_{2}$; however, no traces of the benzylic fluorides $(\mathbf{1 0 1}, \mathbf{m})$ were observed. Interestingly, when the electron-releasing -OMe functional group was in the metaposition, the hydrofluorination reaction gave 10n in 45\% NMR yield, and 33\% isolated yield. Presuming the volatility of 10n to be problematic, we investigated the bulkier substrates 130 and 13p, which also possessed electron releasing - OBn and -OMe groups in their respective meta-positions, and in both cases, the products 10o,p were recovered in moderate yield. ${ }^{24}$

These experiments indicate that substrates bearing electron-neutral or electron-withdrawing substituents are welltolerated in the hydrofluorination reaction. And while substrates with electron-releasing substituents at the para-position were not compatible, substrates with the same electrondonating groups in the meta-position were moderately effective in the reaction. We attribute this trend to the destabilizing effect of electron-donating groups on the aryldiazomethane intermediates, and the decreased stability of the benzyl fluoride products that bear an electron-donating group at the paraposition. Our experimental observations, coupled with the unlikelihood of free carbene formation at this low reaction temperature, led us to propose an ionic mechanism for the oxidative hydrofluorination reaction (Fig. 3). Upon oxidation of hydrazone $\mathbf{1 3}$ to aryldiazomethane intermediate $\mathbf{A}$, iodotoluene and HF (excess) would be generated as by-products. Protonation of the diazo group would give diazonium ion $\mathbf{B}$, from which $\mathrm{N}_{2}$ gas could be expelled upon fluoride attack, leading to benzylic fluoride $\mathbf{1 0 .}$

\section{Conclusions}

In conclusion, we have developed the first use of a hypervalent iodine reagent $\left(\mathrm{TolIF}_{2}\right)$ as both an oxidant and source of fluorine in the hydrofluorination of aromatic aldehyde hydrazones. The one-pot reaction made use of the oxidative potential of the iodane, converting the hydrazone to a diazo group, and generated an excess of the HF by-product which was consumed by a denitrogenative hydrofluorination reaction. The reaction proceeded best with electron-neutral or -withdrawing substituents, and failed with electron-donating groups capable of destabilizing the diazo intermediate. This reaction is a mild, rapid, metal-free and operationally simple alternative to other deoxygenative fluorinating strategies in the synthesis of benzyl fluorides. Further exploration of this reaction, including 
expanding the substrate and functional group scope, is underway and will be disclosed in due course.

\section{Experimental}

A $4 \mathrm{~mL}$ PFA vial containing (difluoroiodo)toluene (1.7 equiv.) was placed under nitrogen and immersed in a pre-heated $40{ }^{\circ} \mathrm{C}$ bath. To this was added a pre-made solution of hydrazone 13a (50 mg, 1.0 equiv.) in $\mathrm{CH}_{2} \mathrm{Cl}_{2}(1.5 \mathrm{~mL})$ via a syringe pump over $\sim 10$ minutes. The reaction was monitored by TLC analysis, and upon consumption of the hydrazone (5-10 $\mathrm{min}$ ), the reaction mixture was cooled to RT and concentrated by rotary evaporation. The resulting crude reaction mixture was purified by flash silica gel chromatography $(10 \%$ EtOAc in hexanes) to provide benzyl fluoride 10a (35 mg) in 74\% yield.

\section{Acknowledgements}

The Natural Sciences and Engineering Research Council (NSERC) of Canada and the University of Waterloo provided financial support for this work. We would like to thank the mass spec facility of the University of Waterloo for sample analysis.

\section{References}

1 K. L. Kirk, Org. Process Res. Dev., 2008, 12, 305.

2 K. Müller, C. Faeh and F. Diederich, Science, 2007, 317, 1881.

3 (a) J. Hu, B. Gao, L. Li, C. Ni and J. Hu, Org. Lett., 2015, 17, 3086; (b) T. Fujiwara and D. O'Hagan, J. Fluorine Chem., 2014, 167, 16; (c) J. Wang, M. Sanchez-Rosello, J. L. Acena, C. del Pozo, A. E. Sorochinsky, S. Fustero, V. A. Soloshonok and H. Liu, Chem. Rev., 2014, 114, 2432; (d) S. Purser, P. R. Moore, S. Swallow and V. Gouverneur, Chem. Soc. Rev., 2008, 37, 320.

4 (a) Y. Zhou, J. Wang, Z. N. Gu, S. N. Wang, W. Zhu, J. L. Acena, V. A. Soloshonok, K. Izawa and H. Liu, Chem. Rev., 2016, 116, 422; (b) K. V. Turcheniuk, V. P. Kukhar, G. V. Roschenthaler, J. L. Acena, V. A. Soloshonok and A. E. Sorochinsky, RSC Adv., 2013, 3, 6693; (c) B. Manteau, S. Pazenok, J. P. Vors and F. R. Leroux, J. Fluorine Chem., 2010, 131, 140; (d) S. Fustero, J. F. Sanz-Cervera, J. L. Acena and M. Sanchez-Rosello, Synlett, 2009, 525.

5 For recent reviews of various fluorination strategies see: (a) P. A. Champagne, J. Desroches, J. D. Hamel, M. Vandamme and J. F. Paquin, Chem. Rev., 2015, 115, 9073; (b) C. Chatalova-Sazepin, R. Hemelaere, J. F. Paquin and G. M. Sammis, Synthesis, 2015, 2554; (c) M. G. Campbell and T. Ritter, Chem. Rev., 2015, 115, 612; (d) X. Liu, C. Xu, M. Wang and Q. Liu, Chem. Rev., 2015, 115, 683; (e) S. Barata-Vallejo, S. M. Bonesi and A. Postigo, Org. Biomol. Chem., 2015, 13, 11153; (f) F. Toulgoat, S. Alazet and T. Billard, Eur. J. Org. Chem.,
2014, 2415; (g) Y. B. Dudkina, M. N. Khrizanforov, T. V. Gryaznova and Y. H. Budnikova, J. Organomet. Chem., 2014, 751, 301; (h) T. Liang, C. N. Neumann and T. Ritter, Angew. Chem., Int. Ed., 2013, 52, 8214.

6 NFSI: (a) E. Differding and H. Ofner, Synlett, 1991, 187; Selectfluor: (b) R. E. Banks, S. N. Mohialdinkhaffaf, G. S. Lal, I. Sharif and R. G. Syvret, J. Chem. Soc., Chem. Commun., 1992, 595; (c) R. E. Banks, J. Fluorine Chem., 1998, 87, 1; $N$-Fluoropyridinium salts: (d) T. Umemoto and K. Tomita, Tetrahedron Lett., 1986, 27, 3271; (e) T. Umemoto, K. Kawada and K. Tomita, Tetrahedron Lett., 1986, 27, 4465. For reviews of N-F reagents see: (f) X.-S. Xue, Y. Wang, M. Li and J.-P. Cheng, J. Org. Chem., 2016, 81, 4280; $(g)$ G. S. Lal, G. P. Pez and R. G. Syvret, Chem. Rev., 1996, 96, 1737.

7 C. F. Ni, M. Y. Hu and J. B. Hu, Chem. Rev., 2015, 115, 765.

8 For TolIF 2 see: (a) R. F. Weinland and W. Stille, Liebigs Ann. Chem., 1903, 328, 132; (b) M. A. Arrica and T. Wirth, Eur. J. Org. Chem., 2005, 395; (c) P. Conte, B. Panunzi and M. Tingoli, Tetrahedron Lett., 2006, 47, 273; (d) T. Inagaki, Y. Nakamura, M. Sawaguchi, N. Yoneda, S. Ayuba and S. Hara, Tetrahedron Lett., 2003, 44, 4117; (e) J. Yu, J. Tian and C. Zhang, Adv. Synth. Catal., 2010, 352, 531; (f) W. B. Motherwell, M. F. Greaney and D. A. Tocher, J. Chem. Soc., Perkin Trans. 1, 2002, 2809.

9 For fluoro iodoxole 8 see: (a) C. Y. Legault and J. Prevost, Acta Crystallogr., Sect. E: Struct. Rep. Online, 2012, 68, 1238; (b) G. C. Geary, E. G. Hope, K. Singh and A. M. Stuart, Chem. Commun., 2013, 49, 9263; (c) V. Matoušek, E. Pietrasiak, R. Schwenk and A. Togni, J. Org. Chem., 2013, 78, 6763; (d) G. C. Geary, E. G. Hope and A. M. Stuart, Angew. Chem., Int. Ed., 2015, 54, 14911; (e) N. O. Ilchenko, B. O. A. Tasch and K. J. Szabo, Angew. Chem., Int. Ed., 2014, 53, 12897; $(f)$ A. Ulmer, C. Brunner, A. M. Arnold, A. Pothig and T. Gulder, Chem. - Eur. J., 2016, 22, 3660.

10 (a) X. Y. Yang, T. Wu, R. J. Phipps and F. D. Toste, Chem. Rev., 2015, 115, 826; (b) G. Landelle, A. Panossian, S. Pazenok, J. P. Vors and F. R. Leroux, Beilstein J. Org. Chem., 2013, 9, 2476; (c) X. F. Wu, H. Neumann and M. Beller, Chem. - Asian J., 2012, 7, 1744; (d) F. L. Qing, Chin. J. Org. Chem., 2012, 32, 815; (e) O. A. Tomashenko and V. V. Grushin, Chem. Rev., 2011, 111, 4475.

11 (a) A. Koperniku, H. Q. Liu and P. B. Hurley, Eur. J. Org. Chem., 2016, 871; (b) A. J. Lin, C. B. Huehls and J. Yang, Org. Chem. Front., 2014, 1, 434; (c) T. Besset, T. Poisson and X. Pannecoucke, Chem. - Eur. J., 2014, 20, 16830; (d) M. C. Belhomme, T. Besset, T. Poisson and X. Pannecoucke, Chem. - Eur. J., 2015, 21, 12836; (e) J. B. Hu, W. Zhang and F. Wang, Chem. Commun., 2009, 7465.

12 (a) G. S. Lal, G. P. Pez, R. J. Pesaresi, F. M. Prozonic and H. Cheng, J. Org. Chem., 1999, 64, 7048; (b) M. J. Koen, F. Le Guyader and W. B. Motherwell, J. Chem. Soc., Chem. Commun., 1995, 1241; (c) H. Koroniak, J. Walkowiak, K. Grys, A. Rajchel, A. Alty and R. Du Boisson, J. Fluorine Chem., 2006, 127, 1245; (d) D. Obermayer, M. Damm and 
C. O. Kappe, Chem. - Eur. J., 2013, 19, 15827; (e) H. Zhao and F. P. Gabbaï, Org. Lett., 2011, 13, 1444; $(f)$ G. Ung and G. Bertrand, Chem. - Eur. J., 2012, 18, 12955.

13 (a) S. Bouvet, B. Pégot, J. Marrot and E. Magnier, Tetrahedron Lett., 2014, 55, 826; (b) M. E. Hirschberg, N. V. Ignat'ev, A. Wenda and H. Willner, J. Fluorine Chem., 2012, 137, 50; (c) R. Mirabdolbaghi, T. Dudding and T. Stamatatos, Org. Lett., 2014, 16, 2790; (d) T. Sawamura, S. Kuribayashi, S. Inagi and T. Fuchigami, Adv. Synth. Catal., 2010, 352, 2757; (e) T. Kitazume and T. Ebata, J. Fluorine Chem., 2004, 125, 1509; $(f)$ M. Mąkosza and R. Bujok, Tetrahedron Lett., 2004, 45, 1385; $(g)$ H. Sun and S. G. DiMagno, J. Am. Chem. Soc., 2005, 127, 2050.

14 (a) H. Doi, I. Ban, A. Nonoyama, K. Sumi, C. Kuang, T. Hosoya, H. Tsukada and M. Suzuki, Chem. - Eur. J., 2009, 15, 4165. For an example of coupling between benzyl carbanion and carbonyl compounds, see: (b) Y. Arroyo, M. A. Sanz-Tejedor, A. Parra and J. L. García Ruano, Chem. - Eur. J., 2012, 18, 5314.

15 (a) J.-J. Ma, W.-B. Yi, G.-P. Lu and C. Cai, Org. Biomol. Chem., 2015, 13, 2890; (b) J. B. Xia, C. Zhu and C. Chen, J. Am. Chem. Soc., 2013, 135, 17494; (c) P. Xu, S. Guo, L. Wang and P. Tang, Angew. Chem., Int. Ed., 2014, 53, 5955; (d) S. Bloom, M. McCann and T. Lectka, Org. Lett., 2014, 16, 6338; (e) J. C. T. Leung, C. Chatalova-Sazepin, J. G. West, M. Rueda-Becerril, J.-F. Paquin and G. M. Sammis, Angew. Chem., Int. Ed., 2012, 51, 10804.

16 (a) E. Emer, J. Twilton, M. Tredwell, S. Calderwood, T. L. Collier, B. Liegault, M. Taillefer and V. Gouverneur, Org. Lett., 2014, 16, 6004; (b) R. Pasceri, H. E. Bartrum,
C. J. Hayes and C. J. Moody, Chem. Commun., 2012, 48, 12077; (c) C. Qin and H. M. L. Davies, Org. Lett., 2013, 15, 6152.

17 A. K. Yadav, V. P. Srivastava and L. D. S. Yadav, Chem. Commun., 2013, 49, 2154.

18 M. E. Furrow and A. G. Myers, J. Am. Chem. Soc., 2004, 126, 12222.

19 (a) K. E. Coffey and G. K. Murphy, Synlett, 2015, 1003; (b) G. K. Murphy, F. Z. Abbas and A. V. Poulton, Adv. Synth. Catal., 2014, 356, 2919; (c) J. Tao, R. Tran and G. K. Murphy, J. Am. Chem. Soc., 2013, 135, 16312.

20 (a) K. E. Coffey, R. Moreira, F. Z. Abbas and G. K. Murphy, Org. Biomol. Chem., 2015, 13, 682; (b) C. Hepples and G. K. Murphy, Tetrahedron Lett., 2015, 56, 4971.

21 G. S. Sinclair, R. Tran, J. Tao, W. S. Hopkins and G. K. Murphy, Eur. J. Org. Chem., 2016, 4603.

22 Murphy lab, unpublished results.

23 (a) M. E. Furrow and A. G. Myers, J. Am. Chem. Soc., 2004, 126, 5436; (b) D. H. R. Barton, J. C. Jaszberenyi, W. S. Liu and T. Shinada, Tetrahedron, 1996, 52, 14673; (c) P. A. S. Smith and E. M. Bruckmann, J. Org. Chem., 1974, 39, 1047; (d) A. Cnossen, J. C. M. Kistemaker, T. Kojima and B. L. Feringa, J. Org. Chem., 2014, 79, 927; (e) L. Lapatsanis, G. Milias and S. Paraskewas, Synthesis, 1985, 513.

24 Hydrazones of 1-naphthaldehyde, pentafluorobenzaldehyde and 3-bromo-4-methoxybenzaldehyde were also effective in the reaction, proceeding in 40-50\% NMR yield. The products were not sufficiently purified to determine isolated yields. 